\title{
Epidemiological profile of spinal cord injuries at a tertiary rehabilitation center in Kuwait
}

\author{
L. Prasad ${ }^{1}$ - S. Al Kandari ${ }^{1}$ - U. Ramachandran ${ }^{1}$ - D. Shehab ${ }^{2}$. S. Alghunaim ${ }^{3}$
}

Received: 8 October 2017 / Revised: 29 November 2017 / Accepted: 5 December 2017

(c) International Spinal Cord Society 2018

\begin{abstract}
Study design Retrospective, descriptive study.

Objective To describe the epidemiological profile of patients with spinal cord injury (SCI) in Kuwait.

Setting Physical Medicine and Rehabilitation Hospital, Kuwait.

Methods Review of medical records of 241 adult patients with SCI admitted during the period 2010-2015. The data collected included gender, age, etiology, neurological and vertebral level of injury and American Spinal Injury Association impairment scale (AIS).

Results There were 155 (64.3\%) traumatic SCI (TSCI) and 86 (35.7\%) non-traumatic SCI (NTSCI) patients. In TSCI, the male to female ratio was 4.3:1, and in NTSCI it was 1.5:1. Road traffic accident was the most common cause of TSCI (52.9\%), followed by fall from height (32.9\%). Acute disc prolapse was the most common cause of NTSCI (29.1\%), followed by degenerative disc disease $(26.7 \%)$ and tumors (17.4\%). Paraplegia $(41.3 \%)$ was more common in TSCI, the level of injury being thoracic in $61 \%$ of cases. Cauda equina syndrome was the most common presentation in NTSCI (40.7\%).

Conclusion Road traffic accident was found to be the main cause of TSCI in Kuwait, whereas acute and degenerative disc lesions were the leading causes in NTSCI. Prevention strategies should be directed toward these causes to reduce the incidence of SCI in Kuwait.
\end{abstract}

\section{Introduction}

Spinal cord injury (SCI) is a devastating condition which results in serious permanent disability. It has a great impact not only on the quality of life of the individual but adds to the financial burden of the family and accounts for significant strain on health care system and the society. This is because in addition to loss of productivity, a person with SCI requires life-long follow-up to prevent and treat secondary complications $[1,2]$. Adequate epidemiologic data

L. Prasad

lataneha@hotmail.com

1 Physical Medicine and Rehabilitation Hospital, Ministry of Health, Andalous, Kuwait

2 Physical Medicine and Rehabilitation Department, Mubarak Al Kabeer Hospital, Jabriya, Kuwait

3 Physical Medicine and Rehabilitation Department, Al Razi Hospital, Shuwaikh, Kuwait regarding traumatic SCI (TSCI) and non-traumatic SCI (NTSCI) are necessary to put prevention strategies in place. It also helps in establishing health policies for acute and rehabilitation care facilities and to project plans for future requirements.

Most of the published research on epidemiology of SCI are from the developed countries [2] and mainly on TSCI $[3,4]$. Epidemiologic data are also available from some countries in the Middle East, including Jordan [5], Turkey [6, 7], Qatar [8], Saudi Arabia [9], Iran [10], and United Arab Emirates [11]. There is relatively less literature on the epidemiology of NTSCI worldwide [3, 4], and to our knowledge none from the Middle East countries. This study provides the epidemiological data of traumatic and nontraumatic SCI in Kuwait to add to the global repository on epidemiology of SCI.

Physical Medicine and Rehabilitation Hospital (PM\&R), is a specialized hospital that provides inpatient rehabilitation services to the whole of Kuwait and receives referrals from its five regional general hospitals. It is an 88 bed hospital with a multidisciplinary rehabilitation team which 
Table 1 Personal and injury characteristics of SCI patients, 2010-2015 $(n=241)$

\begin{tabular}{|c|c|c|c|c|}
\hline & $\begin{array}{l}\text { All } \\
n(\%)\end{array}$ & $\begin{array}{l}\text { Traumatic } \\
n(\%)\end{array}$ & $\begin{array}{l}\text { Non- } \\
\text { traumatic } \\
n(\%)\end{array}$ & $p$-value \\
\hline & $241(100)$ & $155(64.3)$ & $86(35.7)$ & \\
\hline Age in years & & & & $<0.001^{\mathrm{a}}$ \\
\hline$<30$ & $70(29.0)$ & $60(38.7)$ & $10(11.6)$ & \\
\hline $31-45$ & $81(33.6)$ & $57(36.8)$ & $24(27.9)$ & \\
\hline $46-60$ & $53(22.0)$ & $28(18.1)$ & $25(29.1)$ & \\
\hline$>60$ & $37(15.4)$ & $10(6.5)$ & $27(31.4)$ & \\
\hline Mean (SD) & $\begin{array}{l}41.6 \\
(16.3)\end{array}$ & $36.4(14.0)$ & $51.0(16.0)$ & $<0.001^{\mathrm{b}}$ \\
\hline Gender & & & & $0.001^{\mathrm{a}}$ \\
\hline Male & $\begin{array}{l}178 \\
(74.3)\end{array}$ & $126(81.3)$ & $52(60.5)$ & \\
\hline Female & $63(25.7)$ & $29(18.7)$ & $34(39.5)$ & \\
\hline Nationality & & & & $0.001^{\mathrm{a}}$ \\
\hline Kuwaiti & $79(32.8)$ & $39(25.2)$ & $40(46.5)$ & \\
\hline Non-Kuwaiti & $\begin{array}{l}162 \\
(67.2)\end{array}$ & $116(74.8)$ & $46(53.5)$ & \\
\hline Vertebral level & & & & $0.130^{\mathrm{a}}$ \\
\hline $\mathrm{C} 4-\mathrm{C} 7$ & $70(29.0)$ & $47(30.3)$ & $23(26.7)$ & \\
\hline $\mathrm{T} 1-\mathrm{T} 12$ & $87(36.1)$ & $61(39.4)$ & $26(30.2)$ & \\
\hline L1-S5 & $84(34.9)$ & $47(30.3)$ & $37(43.0)$ & \\
\hline $\begin{array}{l}\text { Neurological } \\
\text { Level }\end{array}$ & & & & $0.142^{\mathrm{a}}$ \\
\hline $\mathrm{T}$ & $70(29.0)$ & $47(30.3)$ & $23(26.7)$ & \\
\hline $\mathrm{P}$ & $92(38.2)$ & $64(41.3)$ & $28(32.6)$ & \\
\hline $\mathrm{CE}$ & $79(32.8)$ & $44(28.4)$ & $35(40.7)$ & \\
\hline AIS at admission & & & & $<0.001^{\mathrm{a}}$ \\
\hline $\mathrm{A}$ & $58(35.8)$ & $52(46.8)$ & $6(11.8)$ & \\
\hline B & $10(6.2)$ & $10(9.0)$ & $0(0.0)$ & \\
\hline $\mathrm{C}$ & $47(29.0)$ & $20(18.0)$ & $27(52.9)$ & \\
\hline $\mathrm{D}$ & $47(29.0)$ & $29(26.1)$ & $18(35.3)$ & \\
\hline
\end{tabular}

AIS American Spinal Injury Association Impairment Scale, $C$ cervical, $T$ thoracic, $L$ lumbar, $S$ sacral, $T$ tetraplegia, $P$ paraplegia, $C E$ cauda equina

$p$-values were generated using

${ }^{\text {a }}$ Pearson $\chi^{2}$-test

${ }^{\mathrm{b}}$ Independent $t$-test

includes physiatrists, physiotherapists, occupational therapists, rehabilitation nurses, social workers, prosthetic/ orthotics (P\&O) specialists, speech and swallowing pathologists and psychologists. Acute care of TSCI patients is managed in the regional hospital by the orthopedic surgeon and NTSCI by neurosurgeon. These patients are later transferred to PM\&R Hospital for rehabilitation.

\section{Methods}

All SCI patients above the age of 18 years who were admitted to PM\&R Hospital between January 2010 and December 2015 were included in the study. The data were retrieved from their medical records. The demographic data, including age, gender, etiology, neurological, and vertebral level of injury were noted. The neurological assessment was done as per the International Standards for Neurological Classification of Spinal Cord Injury (ISNCSCI) and AIS grades (American Spinal Injury Association Impairment Scale) were established. Re-admissions of the same individual were excluded from the study.

\section{Statistical methods}

Statistical Package for Social Sciences, (IBM SPSS Statistics 23, IBM Corporation, Armonk, NY, USA 2014) was used for data entry and analysis. Categorical variables were described using numbers and percentages while continuous variables were described with mean and standard deviation. The Pearson $\chi^{2}$-test or Fisher's exact test were used to assess the association between two categorical variables wherever appropriate. Age was compared between two independent groups using independent samples $t$-test, while one-way ANOVA test was used to compare between more than two independent groups. A $p$-value $<0.05$ was considered statistically significant.

We certify that all applicable institutional and governmental regulations concerning ethics were followed for this research.

\section{Results}

A total of 241 patients were admitted to PM\&R Hospital with SCI during the period 2010-2015, among which TSCI were more in number than NTSCI, $155(64.3 \%)$ vs. 86 (35.7\%) (Table 1).

\section{Gender and age}

Males outnumbered females with an overall ratio of 2.8:1. In TSCI, the male to female ratio was $4.3: 1$, whereas in NTSCI it was 1.5:1. This difference in male to female ratio between TSCI and NTSCI was statistically significant ( $p=$ 0.001). A significant difference was also noted between the TSCI and NTSCI patient groups in their age distribution ( $p$ $<0.001$ ). TSCI showed more prevalence in the younger population, with mean age of $36.4 \pm 14$ years, whereas, the mean age for NTSCI group was $51 \pm 16$ years (Table 1 ). 
Fig. 1 Causes for traumatic and non-traumatic SCI
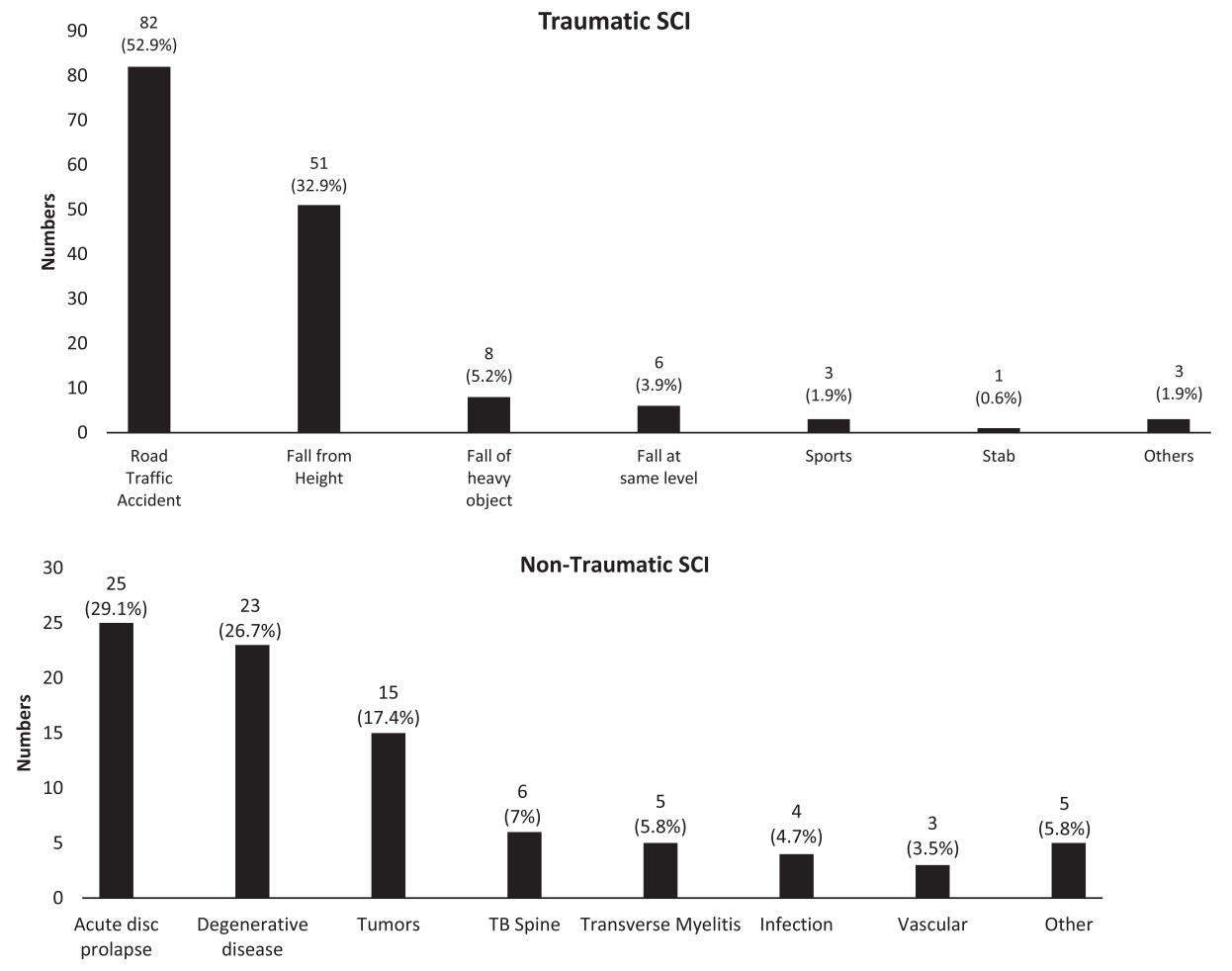

\section{Etiology}

TSCI causes were mainly from road traffic accident (RTA) $82(52.9 \%)$ and fall from height 51 (32.9\%) while nontraumatic causes were acute disc prolapse 25 (29.1\%), degenerative disc disease 23 (26.7\%), and tumors 15 (17.4\%) (Fig. 1)

\section{Level of injury and neurological level}

In TSCI thoracic vertebral fractures were most common 61 (39.4\%), followed by an equal number of lumbar $47(30.3 \%)$ and cervical fractures 47 (30.3\%). In NTSCI, lumbar level lesions were more common $37(43.0 \%)$ followed by thoracic $26(30.2 \%)$ and cervical 23 (26.7\%) (Table 1). According to neurological level, paraplegia was more common in TSCI 64 (41.3\%) followed by tetraplegia $47(30.3 \%)$ and cauda equina syndrome $44(28.4 \%)$. In the case of NTSCI cauda equina syndrome was the most common presentation 35 (40.7\%) followed by paraplegia $28(32.6 \%)$ and tetraplegia 23 (26.7\%) (Table 1).

\section{ASIA impairment scale (AIS)}

There was a significant difference in AIS grades on admission between TSCI and NTSCI patient groups $(p<$ $0.001)$. AIS A was more in numbers in TSCI, $52(46.8 \%)$ compared to only $6(11.8 \%)$ in NTSCI. Among the incomplete NTSCI cases, AIS grades C 27 (52.9\%) and D $18(35.3 \%)$ were more common (Table 1$)$.

\section{Discussion}

Total of 241 patients with SCI were admitted to PM\&R Hospital for rehabilitation from 2010 to 2015 of which 155 were traumatic and 86 non-traumatic SCI. The male to female ratio of 4.3:1 for TSCI in Kuwait has now decreased compared to the ratio of $7: 1$ reported in a retrospective study done from the same center during the period 1991-1999 [12]. The ratio is also lower than that seen in other Middle East countries which ranges from 9:1 in Saudi Arabia [9] and in United Arab Emirates [11] to 8.3:1 in Qatar [8] and 5.6:1 in Iran [10]. Our ratio is comparable to the general international trend as reported in a review of literature on epidemiology of SCI [13]. In non-traumatic cases of SCI the male to female ratio was 1.5:1 since both genders have similar risk factors related to advancing age $[14,15]$.

TSCI was predominant in young males with mean age of 36.4 years as reported in most countries [2, 5-12, 16-19]. Countries like Finland [20] and Korea [21] show a trend toward higher age group with a mean above 40 years, the highest being reported in China with a mean $50.1 \pm 15.5$ years [22].

RTA was the most common etiology (52.9\%) in Kuwait (Fig. 1) similar to the reports from most countries 


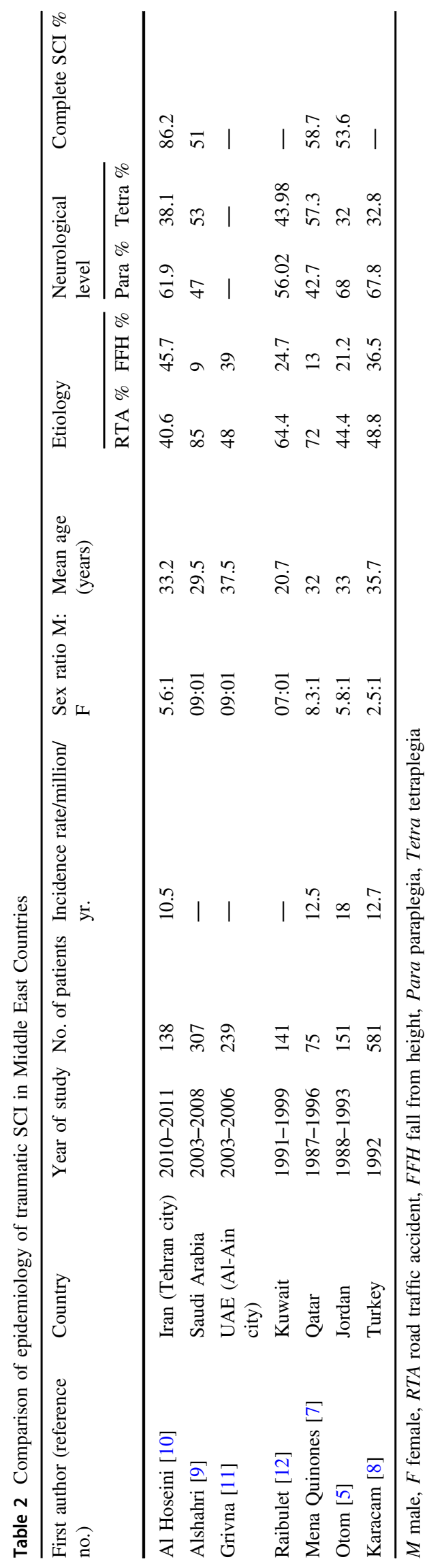

worldwide $[2,5,7-9,11-13,16-19,21]$. The rate of RTA is much less compared to other Middle Eastern countries [23] like Saudi Arabia (85\%) [9] and Qatar (72\%) [8]. The present study shows that the number of SCI due to RTAs in Kuwait have reduced to $52.9 \%$ from $64.4 \%$ which was reported in in a study from the same center 15 years ago [12].

In TSCI, low level injuries-paraplegics and cauda equina syndromes constituted $69.7 \%$, similar to other countries in the region-Jordan [5], Turkey [8], Iran [10], and United Arab Emirates [11]. However, Qatar [7] and Saudi Arabia [9] reported higher number of tetraplegics. In NTSCI mainly incomplete injuries AIS grades C and D (95.7\%) were observed. Table 2 shows comparative epidemiological data from some of the Middle East countries.

The most common etiology for NTSCI in Kuwait was found to be acute disc prolapse (29\%), followed by degenerative disc disease (26.7\%). Cauda equina syndrome secondary to acute lumbar disc prolapse was the most common neurological presentation (40.7\%). An epidemiological study on NTSCI involving nine countries from Western Europe to North America, as well as Australia and India [24] reported degenerative disease (30.8\%) as the most common etiology followed by malignant tumors $(16.2 \%)$.

\section{Limitations}

This is a single center, hospital based, retrospective, descriptive study from a tertiary rehabilitation center in Kuwait, providing comprehensive inpatient rehabilitation program for SCI in Kuwait. Our data include most of the patients who had moderate to severe SCI. However, patients with minor neurological deficits following SCI who were managed in the regional hospital or those who attended only out-patient services in our center could not be included in the study as their data was not accessible. SCIs associated with severe injuries resulting in death at the site of accident, during transportation or in the acute stage are not accounted for in our study.

\section{Conclusion}

Road traffic accidents were found to be the main cause of traumatic SCI. Acute and degenerative disc lesions were the predominant cause for non-traumatic SCI. Prevention strategies should be formulated to focus on these causes to reduce the incidence of SCI in Kuwait. Establishing a spinal cord injury national registry covering all the hospitals in Kuwait would provide a clearer picture on the epidemiological profile and help to improve the services for SCI rehabilitation in Kuwait. 


\section{Compliance with ethical standards}

Conflict of interest The authors declare that they have no conflict of interest.

\section{References}

1. Ackery A, Tator C, Krassioukov A. A global perspective on spinal cord epidemiology. J Neurotrauma. 2004;21:1355-70.

2. Wyndaele M, Wyndaele J-J. Incidence, prevalence and epidemiology of spinal cord injury: what learns a worldwide literature survey? Spinal Cord. 2006;44:523-508.

3. Van den Berg MEL, Castellote JM, Mahillo-Fernandez I, de Pedro, Cuesta J. Incidence of spinal cord injury worldwide: a systematic review. Neuroepidemiology. 2010;34:184-92.

4. Kennedy P, Chessel ZJ. Traumatic versus non-traumatic spinal cord injuries: are there differential rehabilitation outcomes? Spinal Cord. 2013;51:579-83.

5. Otom AS, Doughan AM, Kawar JS, Hattar EZ. Traumatic spinal cord injuries in Jordan—an epidemiological study. Spinal Cord. 1997;35:253-5.

6. Karamehmetoglu SS, Nas K, Karacan I, Sarac AJ, Koyuncu H, Ataoglu S, et al. Traumatic spinal cord injuries in Southeast Turkey: an epidemiological study. Spinal Cord. 1997;35:531-3.

7. Mena Quinones PO, Nassal M, Al Bader KI, Al Muraikhi AE, Al Kahlout SR. Traumatic Spinal Cord Injury in Qatar: an epidemiological study. The Middle East. J Emerg Med. 2002;2:27-29.

8. Karacan I, Koyuncu H, Pekel O, Sumbuloglu G, Kirnap M, Dursun $\mathrm{H}$, et al. Traumatic spinal cord injuries in Turkey: a nation-wide epidemiological study. Spinal Cord. 2000;38:697-701.

9. Alshahri SS, Cripps RA, Lee BB, Al-Jadid M. Traumatic spinal cord injury in Saudi Arabia: an epidemiological estimate from Riyadh. Spinal Cord. 2012;50:882-4.

10. Sharif-AlHoseini M, Rahimi-Movaghar V. Hospital-based incidence of traumatic spinal cord injury in Tehran, Iran. Iran J Publ Health. 2014;43:331-41.

11. Grivna M, Eid HO, Abu-Zidan FM. Epidemiology of spinal injuries in the United Arab Emirates. World J Emerg Surg. 2015;10:20.
12. Raibulet T, Fakhri S, Khamees MF, Eyadeh AA. Spinal cord injury patients in the physical medicine and rehabilitation, Kuwait- a nine year retrospective study. Kuwait Med J. 2001;33:211-5.

13. DeVivo MJ. Epidemiology of traumatic spinal cord injury: trends and future implications. Spinal Cord. 2012;50:365-72.

14. Osterthun R, Post MWM, van Asbeck FWA. Characteristics, length of stay, and functional outcome of patients with spinal cord injury in Dutch and Flemish rehabilitation centers. Spinal Cord. 2009;47:339-44.

15. Van den Berg MEL, Castellote JM, Mahillo-Fernandez I, PedroCuesta J. Incidence of nontraumatic spinal cord injury: a Spanish cohort study (1972-2008). Arch Phys Med Rehabil. 2012;93:325-31.

16. Pirouzmand F. Epidemiological trends of spine and spinal cord injuries in largest Canadian adult trauma center from 1986 to 2006. J Neurosurg Spine. 2010;12:131-40.

17. O'Connor RJ, Murray PC. Review of spinal cord injuries in Ireland. Spinal Cord. 2006;44:445-8.

18. Knutsdottir S, Thorisdottir H, Sigvaldason K, Jonsson H Jr, Bjornsson A, Ingvarsson P. Epidemiology of traumatic spinal cord injuries in Iceland from 1975 to 2009. Spinal Cord. 2012;50:123-6.

19. Nwankwo OE, Uche EO. Epidemiological and treatment profiles of spinal cord injury in southeast Nigeria. Spinal Cord. 2013;5:448-52.

20. Ahoniemi E, Alaranta H, Hokkinen E-M, Valtonen K. Kautiainen, Incidence of spinal cord injuries in Finland over a 30 year period. Spinal Cord. 2008;46:781-4.

21. Shin JC, Kim DH, Yu SJ, Yang HE, Yoon SY. Epidemiologic change of patients with spinal cord injury. Ann Rehabil Med. 2013;37:50-56.

22. Zhou Y, Wang X-B, Kan S-L, Ning G-Z, Li Y-L, Sun J-C, et al. Traumatic spinal cord injury in Tianjin, China: a single center report of 354 cases. Spinal Cord. 2016;54:670-4.

23. Lee BB, Cripps RA, Fitzharris M, Wing PC. The global map for traumatic spinal cord injury epidemiology: update 2011, global incidence rate. Spinal Cord. 2014;52:110-6.

24. New PW, Reeves RK, Smith E, Townson A, Eriks-Hoogland I, Gupta A, et al. International retrospective comparison of inpatient rehabilitation for patients with spinal cord dysfunction epidemiology and clinical outcomes. Arch Phys Med Rehabil. 2015;96:1080-7. 